\title{
Atividade docente, vivências e mediações no primeiro ano do ensino fundamental do município de Natal/RN
}

\author{
Letícia Raboud M. de Andrade ${ }^{1}$, https://orcid.org/0000-0003-4870-8537 \\ Jorge Tarcísio da Rocha Falcão", https://orcid.org/0000-0002-2798-3727
}

\begin{abstract}
Resumo
A democratização da educação apresenta interesses contraditórios, envolvendo mecanismos de reprodução das desigualdades e forças voltadas à transformação social. Neste cenário, a precarização do trabalho docente pode produzir situações de alienação que repercutem nas vivências laborais. Busca-se analisar a atividade docente, vivências, mediações, impedimentos e potenciais pelo referencial teórico da clínica da atividade através da técnica de Instrução ao Sósia que permite o diálogo reflexivo do trabalhador com sua prática. Duas professoras do primeiro ano do município de Natal/RN participaram da pesquisa. Os resultados revelaram diferentes modos de relação com a atividade: uma lógica de produção e controle da turma, trazendo impedimentos da ação, e a compreensão de centralidade do aluno no processo de aprendizagem, demonstrando dinamismo e acesso a recursos de enriquecimento da ação. A inserção em um coletivo de trabalho revela-se fundamental para o desenvolvimento dos trabalhadores e sua atividade.
\end{abstract}

Palavras-chave: Trabalho docente; Psicologia histórico-cultural; Psicologia do trabalho.

\section{Teaching activity, experiences and mediations in Natal/RN first grade}

\begin{abstract}
The democratization of education presents contradictory interests, involving mechanisms of reproduction of inequalities and forces geared to social transformation. In this scenario, the precariousness of teaching work can produce alienation situations that have repercussions on work experiences. It seeks to analyze the teaching activity, experiences, mediations, impediments, and potentials, by the theoretical reference of the clinic of the activity through the technique of instruction to the look-alike that allows the reflective dialogue of the worker with his practice. Two teachers from the first year of natal / rn participated in the research. The results revealed different modes of relation with the activity: a logic of production and control of the class, bringing impediments to the action and the understanding of student centrality in the learning process, demonstrating dynamism and access to enrichment resources of the action. The insertion in a collective of work proves to be fundamental for the development of the workers and their activity.
\end{abstract}

Keywords: teaching work; Historical-cultural Psychology; Psychology of work.

\section{Actividad docente, vivencias y mediaciones en el primer curso de la enseñanza primaria del municipio de Natal/RN}

\section{Resumen}

La democratización de la educación presenta intereses contradictorios, abarcando mecanismos de reproducción de las desigualdades y fuerzas volcadas a la transformación social. En este escenario, la precarización de la labor docente puede producir situaciones de alienación que repercuten en las vivencias laborales. Se busca analizar la actividad docente, vivencias, mediaciones, impedimentos y potenciales, por el referencial teórico de la clínica de la actividad por intermedio de la técnica de Instrucción al Sosia que permite eldiálogo reflexivo del trabajador con su práctica. Dos profesoras del primero curso del municipio de Natal/RN participaron de la investigación. Los resultados revelaron distintos modos de relación conla actividad: una lógica de producción y control del grupo, trayendo impedimentos de la acción; Y la comprensión de centralidad do alumno en el proceso de aprendizaje, demostrando dinamismo y acceso a recursos de enriquecimiento de la acción. A inserción en un colectivo de trabajo se revela fundamental para el desarrollo de los trabajadores y su actividad.

Palabras clave: Labor docente; Psicología histórico-cultural; Psicología del trabajo.

1 Universidade Federal do Rio Grande do Norte - Natal - RN - Brasil; lelermandrade@gmail.com; falcão.jorge@gmail.com 


\section{Introdução}

Considerando os desafios, potenciais e contradições que permeiam o contexto da educação pública básica, o presente trabalho se debruça sobre a atividade docente, mediações e vivência por duas professoras do primeiro ano do ensino fundamental da rede pública municipal de Natal, levando em consideração as particularidades desta etapa. A abordagem teórico-metodológica empregada é a da clínica da atividade, que será mais bem explicitada adiante, e a perspectiva histórico-cultural de Vigotski.

Os parágrafos seguintes farão um delineamento do cenário da educação pública, implicações e características do trabalho docente, além de explorar a perspectiva da alienação segundo Leontiev, o quadro teórico da clínica da atividade e o conceito de vivência de Vigotski.

A atividade docente, no contexto da educação pública, é atravessada por contradições envolvendo a proposta de democratização da educaçãopelo desafio da universalização e qualidade. Proposta consolidada pela promulgação da constituição de 1988, que reconhece oficialmente a educação enquanto direito de todos e dever do Estado, e promulgação, em 1996, da Lei de Diretrizes e Bases da Educação Nacional (Lei 9.394/96), que define e regulariza a organização do sistema educativo brasileiro. Nas reformas e políticas empreendidas estão em jogo interesses voltados para o mercado no sentido do funcionamento à sua semeIhança e reprodução da força de trabalho para o capital, bem como interesses e negociações da sociedade civil na luta pela educação enquanto direito (Lopes \& Caprio, 2008).

Nesse contexto contraditório estão envolvidas condições de precarização da profissão docente pelo desinvestimento a nível financeiro e gerencial do Estado, que não garante salários e condições satisfatórias de trabalho aos profissionais da educação nas diferentes redes (Lopes \& Caprio, 2008). Está igualmente implicado o aumento das atribuições da escola e intensificação do trabalho dos professores, que devem lidar com realidades sociais complexas e uma lógica de exclusão naescola, tendo em vista o maior investimento na permanência dos alunos, ajuste idade-série e negligência nas condições desta permanência (Paparelli, 2009). Instituições e professores estão ainda sujeitos a avaliações externas com viés de responsabilização individualizante e uma lógica de produtividade passível de dirigir esforços à aquisição de conhecimentos mínimos pelas crianças em detrimento do domínio de conteúdos e desenvolvimento de potenciais (Dourado \& Oliveira, 2009).

Para além de um simples reflexo das contradições sociais, as contradições do trabalho docente se arraigam nas tensões inerentes ao ato de ensino-aprendizagem (Charlot, 2008). O autor indica o paradoxo do professor herói versus vítima, herói da pedagogia e vítima mal paga e sempre criticada, colocando que a situação de estar preso entre discursos contraditórios gera vitimização, indignação e desmobilização profissional. Outra tensão/contradição comum diz respeito às práticas tradicionais versus as construtivistas, sendo a pedagogia tradicional caracterizada por posturas de rigor e autoridade, baseando-se na explicação dos conteúdos e regras da atividade para aplicação pelos alunos, enquanto o construtivismo foca na atividade do aluno e sua mobilização intelectual na busca por respostas, sem deixar de lado o compartilhamento do conhecimento sistematizado produzido pelo homem. Como traz Charlot (2008, p.25)“... a questão fundamental não é saber se a professora é "tradicional" ou "construtivista", mas como ela resolve duas tensões inerentes ao ato de ensino e ao de educar.", uma vez que "Ensinar é ao mesmo tempo, mobilizar a atividade dos alunos para que construam saberes e transmitir-lhes um patrimônio de saberes sistematizados legado pelas gerações anteriores de seres humanos.", devendo ser o docente professor de conteúdos e de questionamentos.

Com o intuito de fazer uma leitura mais ampla da atividade docente e de suas formas de vivência, serão trazidas diferentes compreensões sobre o fenômenodaalienação no trabalho, a primeirareferindo-se a alienação sob o capitalismo, baseada na exploração de uma parte da população (proletariado) por outra (burguesia), que ocorre pela sua compartimentalização. Planejamento e execução, trabalho manual e intelectual tornam-se momentos separados, o trabalhador é destituído de seu saber (Asbahr, 2005). Nesse quadro, o trabalho pedagógico apresenta particularidades, como ser não produtivo, em se tratando da educação pública, pois não visa ao lucro.No trabalho pedagógico, o produto (aprendizagem) e o ato de produção (ensino) não podem ser separados. Paro (1993) coloca o aluno como objeto de trabalho, pois sobre ele incide o ofício do educador que o transforma para além da aula, sendo igualmente sujeito ativo de seu processo de aprendizagem e co-produtor deste. A impossibilidade de separação completa entre produto e produção no trabalho docente faz com que o Capital não exerça controle direto sobre o mesmo, fazendo-o de forma política e ideológica (Asbahr, 2005).

Sem desconsiderar a perspectiva trazida, Leontiev (2004) traz uma compreensão de alienação envolvendoo conceito de significaçãorelacionado a um sistema de significações existente, elaborado historicamente, do qual o sujeito se apropria atribuindo-lhe um sentido pessoal. A significação social do trabalho docente está relacionada ao "ato de produzir, direta e intencionalmente, em cada indivíduo singular, a humanidade que é produzida histórica e coletivamente pelo conjunto dos homens" (Saviani, 2000, p.17), sendo a escola uma instituição privilegiada em relação às possibilidades de humanização do homem, pois permite uma organização consciente dos processos de formação dos indivíduos (Moretti, Asbahr, \& Rigon, 2011). Leontiev (2004) compreende o processo de alienação quando, na atividade laboral, o sentido pessoal da ação se distancia do seu significado social. No trabalho docente, este distanciamento pode traduzir-se pela execução de operações automatizadas, sem sentido para os alunos, repetição de conteúdos e reprodução do livro didático (Asbahr, 2005).

Será doravante apresentadaa perspectiva da clínica da atividade, cujo principal expoente é o psicólogo francês Yves Clot, permitindo uma aproximação da atividade docen- 
te, sua vivência e medições. Trata-se deuma clínica do trabaIho que tem como referências a ergonomia e psicopatologia francesas e fundamenta-se na abordagem histórico-cultural de Vigotski, visando ao desenvolvimento da atividade e pela atividade através da ampliação da potência de ação de sujeitos e coletivos (Clot, 2008). Neste enquadre, o sofrimento é concebido enquanto atividade contrariada, desenvolvimento impedido (Clot, 1999). Se os trabalhadores não dispõem de recursos para fazer frente aos impasses do real, ou meios para desenvolver estes recursos, encontram-se em situação de impedimento (Silva \& Ramminger, 2014). A saúde é compreendida na perspectiva de Canguilhem (2009), não como ausência de doença, mas como capacidade normativa, de estabelecimento de normas de vida diante das dificuldades, gerando desenvolvimento. Nessa ótica são problemáticas as situações de entrave e enrijecimento.

A clínica da atividade procura intervir junto aos trabaIhadores tendo em vista a ampliação da consciência e reflexão sobre a atividade de modo que a experiência vivida possa ser ou vir a ser meio de viver outras experiências (Clot, 2008), o autor menciona Vigotski na compreensão de que uma ação passada pelo crivo do pensamento transforma-se em outra, por sua vez, refletida. Clot (2008) traz ainda a percepção de trabalho bem feito enquanto referenciado por uma tradição profissional viva (coletiva) como norte para o "bem estar". O coletivo é percebido como recurso para o desenvolvimento dos indivíduose da atividade, produzindo embates sobre os quais se investe e se trabalha, "A saúde se degrada no ambiente de trabalho sempre que um coletivo profissional torna-se uma coleção de indivíduos expostos ao isolamento" (Clot, 2002, p.4).

Serão agora desenvolvidos alguns operadores teóricos da clínica da atividade, como o conceito de real da atividade, que compreende a atividade para além da tensão entre o prescrito e o realizado, envolvendo os conflitos do real, incluindo além do que é feito: o que não se faz, o que se faz a contragosto, o que se busca fazer sem conseguir etc. (Clot, 2008), envolvendo uma dimensão subjetiva da atividade. Compreende-se ainda uma arquitetura da atividade de trabalho composta por quatro instâncias que interagem de forma dinâmica: impessoal, relativa ao prescrito que orienta o ofício, também passível de transformação; pessoal, referente à atividade sobre/por si mobilizada e sua expressão singular; interpessoal, dirigida ao outro; e transpessoal, referente à história coletiva de um grupo profissional, com suas potencialidades e contradições (Clot, 1999).

A dimensão transpessoal refere-se ao conceito de gênero profissional da atividade, que diz de uma memória coletiva dinâmica de saberes e gestos pertencentes a um coletivo de trabalho, marcando o pertencimento a um grupo e orientando a ação (Clot, 2008). Dá-se o nome de estilo pessoal àreformulação do gênero em situação, ao seu ajuste pelo trabalhador para torná-lo instrumento da ação, envolvendo uma margem de autonomia e criação que se nutre do gênero profissional (Clot, 2008). Clot (2002) compreende que há degradação da saúde quando a história do gênero profissional encontra-se suspensa e "Cada um individualmente se encontra então confrontado às más surpresas de uma organização do trabalho que deixa "sem voz" face ao real" (Clot, 2002, p.4).

Por fim, a clínica da atividade compreende a centralidade do trabalho no desenvolvimento e constituição da subjetividade humana preenchendo uma função psicológica que "põe o sujeito à prova de suas obrigações práticas e vitais com relação aos outros e com relação ao mundo" (Clot, 1999, p.201), constituindo um dos gêneros de referenciamento mais fundamentais da vida psicossocial, que liga cogeneticamente sujeito/coletivo e sociedade, ainda que essa conexão possa se estabelecer de forma alienada.

Acrescentando à perspectiva da clínica da atividade, apresenta-se o conceito vigotskiano de vivência, do russo perezhivanie, compreendido como unidade dialética da consciência humana, estabelecido na dinâmica da relação entre o ambiente social e o lugar ocupado pelo indivíduo, como um prisma que refrata a experiência (Veresov, 2014). Veresov (2014) coloca a compreensão de Vigotski das relações sociais enquanto fonte das funções mentais superiores pela experiência de drama, colisão dramática pessoal e emocionalmente vivenciada interpsicologicamente $e$ intrapsicologicamente com potencial para produzir desenvolvimento. Veresov (2014) compreende a vivência de duas formas: comofenômeno, referindo-se ao prisma e ao modo como os indivíduos vivem situações e contextos onde estão inseridos, e como conceito, referindo-seà vivência dramática, envolvendo drama, conflitos que ensejam transformação e desenvolvimento.

A clínica da atividade é capaz de produzir vivência dramática pelo confronto que se propõe a fazer de sujeitos e coletivos entre si e com a própria atividade, podendo mobilizar transformações. A abordagem permite ainda entrever a vivência como prisma, lugar ocupado diante de um contexto, constituindo-se como ferramenta de pesquisa e intervenção.

Considerando o foco do trabalho na atividade de professoras do primeiro ano do ensino fundamental da rede municipal de Natal/RN, os parágrafos seguintes destinam-se a trazer condições e características deste cenário.

Professores do $1^{\circ}$ ao $5^{\circ}$ ano são responsáveis por uma turma, lecionando diferentes disciplinas (português, matemática, ciências, história e geografia). Com a lei federal 11.247, promulgada em 2006, houve inclusão de crianças de 6 anos no ensino fundamental, que passaram a frequentar o primeiro ano do ensino fundamental, política importante considerandoa possibilidade de socialização e inserção na cultura escolar mais cedo, além de produzir melhores condições de alfabetização (Mainardes \& Stremel, 2012).

Para os anos iniciais do ensino fundamental $\left(1^{\circ}\right.$ ao $3^{\circ}$ ) existe a proposta de um currículo comum, ainda que não oficializado, pelo documento "Direitos de Aprendizagem no Ciclo de Alfabetização", cuja meta é a alfabetização até os 8 anos, divulgado pelo Ministério da Educação (MEC) em dezembro de 2012, e relacionado, dentre outros, ao Pacto Nacional pela Alfabetização na Idade Certa (PNAIC), programa de formação continuada de professores oferecido pelos sistemas de ensino. $\mathrm{O}$ documento é considerado relevante, 
embora necessite ser discutido e analisado (Alferes \& Mainardes, 2014).

Em abril de 2017 foi entregue pelo MEC ao Conselho Nacional de Educação a versão final da Base Nacional Comum Curricular, iniciativa com potencial para contribuir no processo de democratização da educação, embora esteja igualmente vinculada a avaliações que visam à aquisição de saberes mínimos pelos alunos e ampliação de controle e padronização de conteúdos e do trabalho docente. Apesar dos riscos implicados no estabelecimento de um currículo comum, sua ausência também pode contribuir para um cenário de orientação fragmentado e contraditório, além de não estar isenta da influência de avaliações.

\section{Método}

O presente trabalho se insere no quadro de uma dissertação de mestrado cujo objetivofoi analisar a atividade de professores do ensino fundamental I da rede pública municipal de Natal, desvelando vivências, mediações, impedimentos e potenciais, levando em consideração condições e percepções sobre a atividade.

A pesquisa compreendeu uma etapa quantitativa que avaliou, dentre outros elementos, os perfis psicossociais de trabalho dos professores, envolvendo a condição de risco psicossocial, por meio do instrumento Job Content Questionnaire (DARES-DRESS, 2008), de uma amostra representativa composta por 172 professores do ensino fundamental I da rede pública municipal de Natal/RN. Embora a etapa quantitativa não seja o foco do artigo, os perfis gerados pelo JCQ serão brevemente delineados, por terem servido como importante critério para a seleção das professoras participantes da pesquisa para a clínica da atividade. $\mathrm{O}$ instrumento avalia três dimensões do ambiente psicossocial de trabalho: a demanda psicológica da atividade, ou em que medida a atividade exige em termos de quantidade, rapidez, complexidade e perturbações; a atitude de decisão, referente ao controle sobre a própria atividade, recurso às competências e desenvolvimento; e o suporte social recebido de colegas e superiores. Um trabalho com alta demanda psicológica e baixa latitude de decisão configura um perfil de risco psicossocial, o elevado suporte social atenuando o quadro e sua escassez agravando-o. A baixa demanda psicológica e alta latitude de decisão constituem um perfil de baixo risco psicossocial. A alta demanda psicológica e latitude de decisão formam um perfil de trabalho ativo, enquanto a baixa demanda psicológica e latitude de decisão sinalizam um perfil de trabalho passivo.

Para a pesquisa foram selecionadas duas professoras do primeiro anodo ensino fundamental, de instituições diferentes e pertencentes a perfis psicossociais opostos. Uma em situação de risco psicossocial e outra de baixo risco, permitindo a análise de perspectivas diferentes da atividade e vivências expressas da mesma. Foi utilizada a entrevista de instrução ao sósia, de caráter clínico qualitativo, que compõe o ferramental metodológico da Clínica da Atividade.
A técnica consiste basicamente na proposta aos trabalhadores da seguinte situação fictícia: "Suponha que eu serei seu sósia e que amanhã vou substituí-lo em seu local de trabaIho. Quais instruções você deveria me transmitir para que ninguém percebesse a substituição?". O sósia (pesquisador) tem a função de fazer perguntas ao instrutor (profissional), interessar-se pelos detalhes da atividade, explorar as possibilidades, buscar o "como" ao invés do "porquê", favorecendo o acesso ao real da atividade, seus explícitos e implícitos. Antes da instrução, uma situação de trabalho deve ser delimitada com as profissionais, enfocando momentos significativos da atividade, centrais e/ou desafiantes. Embora a clínica da atividade envolva o trabalho com coletivos, as entrevistas foram realizadas individualmente com cada professora, tendo em vista problemas de deslocamento e disponibilidade de tempo para um encontro entre as duas.

Quando o trabalhador assume a posição de instrutor de sua própria atividade ele deve referir-se ao sósia na segunda pessoa, utilizando "tu" ou "você", ao invés de "eu", por exemplo: "Então você irá descer as escadas", em vez de "Então eu irei descer as escadas". Trata-se de projetar a atividade no futuro, no sósia, em posição dialógica com um "eu" social, conforme relata Clot (1999) ao usar as palavras de Vigotski sobre promover "um contato social consigo mesmo". O exercício permite ao trabalhador acessar sua atividade indiretamente, pelo sósia, aproximando-se de modo novo da mesma e permitindo diferentes leituras e tomadas de consciência, bem como revelando caminhos de pensamento e ação confrontados às situações laborais.

A entrevista foi gravada e transcrita pela pesquisadora, e posteriormente enviada às professoras, caso pudessem ler. A segunda e última entrevista com as profissionais envolveu a seleção prévia de trechos da primeira entrevista considerados representativos para leitura e confrontação pelas docentes. $\mathrm{O}$ momento foi igualmente gravado e transcrito para análise da pesquisadora.

A análise envolveu a identificação das instâncias de referência da atividadena entrevista: o prescrito (impessoal), a atividade dirigida a si e por si (pessoal), a atividade dirigida ao outro (interpessoal) e o gênero profissional (transpessoal), bem como as relações entre estas instâncias, conflitos e contradições, impedimentos e possibilidades, revelando o campo do real da atividade, ou seja, além do prescrito e do realizado, o que se fez a contragosto ou sem acreditar, o que não se conseguiu fazer, o que se queria ter feito etc. A análise levou em consideração ainda o contexto e características do trabalho docente, desvelando vivências, mediações e pistas de sua constituição.

\section{Resultados e Discussão}

Serão apresentados e discutidos os registros das entrevistas realizadas com cada professora, seguido de um paralelo entre as duas experiências.A primeira profissional, que será chamada de $\mathrm{S}$, pertence ao perfil de risco psicossocial e reconhece um baixo suporte social em seu 
trabalho. S tem 43 anos, leciona há nove anos, sua turma possui cerca de 25 alunos, trabalha no contraturno em outra instituição distante da primeira e de onde habita. Durante a etapa de seleção da situação a ser explorada na instrução ao sósia, $\mathrm{S}$ trouxe suas primeiras experiências no município enquanto professora de um $5^{\circ}$ ano com 38 alunos em situações heterogêneas de aprendizagem, colocando as dificuldades, sofrimento e frustração, que a deixaram "sem voz" face ao real. A docente também trouxe problemas de saúde ligados ao trabalho, como fendas nas cordas vocais, dores de cabeça e no corpo e falou de falta de acompanhamento e valores das famílias dos alunos. A situação escolhida para ser explorada por $\mathbf{S}$ foi a atividade de carta ao Papai Noel do projeto dos Correios em que as crianças devem escrever uma carta e fazer um pedido, podendo ser respondidas e ganhar um presente.

Durante a instrução ao sósia, $\mathrm{S}$ mencionou a importância de motivar os alunos para a atividade e as dificuldades envolvidas, trazendo: "Você faz de conta que acredita (que os alunos estão interessados), porque senão você não faz. $E$ você tem que fazer de qualquer jeito" (Entrevista realizada em 11/11/2016).

O trecho revela o real da atividade, o que se faz sem se acreditar. Fazer de conta é uma condição mobilizada (pessoal) para "conseguir" fazer a atividade (prescrito), embora se trate de uma atividade esvaziada de significado social, levando em consideração a compreensão de Leontiev (2004), já que o sentido pessoal da atividade não condiz com seu significado.

S se queixa do número de alunos na turma e seus relatos trazem a interpelação contínua para manter o controle da sala, conforme os trechos:

Se você não demonstrar liderança e domínio, você jamais educará essas crianças... Porque a questão da aprendizagem começa pelo estímulo, mas também, acima de tudo, pela disciplina. Você precisa estar aberto pra receber o que o outro vai te dar e você só se abre se você for convencido.

Esse domínio do professor precisa existir, do contrário a atividade morre.

O controle (dimensão interpessoal, dirigido aos alunos) é percebido como vital para a realização da atividade (prescrito), no entanto pode aprisioná-la e travar sua fluidez. O uso de palavras como "domínio" e "convencimento" tende a uma percepção passiva dos alunos.Sobre sua atividade $\mathbf{S}$ traz: "E o trabalho do professor é essa constante retomada até que você consiga vencer eles pelo cansaço. E aí você consegue fazer a produção".

Trabalhar é uma batalha que precisa ser vencida, e produzir assume o papel de prescrito para a atividade, aprisionando as outras instâncias e implicando em uma visão passiva dos alunos (vencê-los pelo cansaço, instância interpessoal) que, contudo, precisam ser sujeitos ativos do seu processo de aprendizagem. Ilustra-se uma atividade enrijecida. Pode haver ruptura entre significado e sentido do trabalho,conforme compreendido por Leontiev (2004), caso o sentido assumido, seja a produção material da atividade ao invés da produção de desenvolvimento (significado social).

Na segunda etapa da entrevista, de confrontação a trechos da atividade, S identificou elementos centrais de sua prática profissional: "Então é a questão da motivação, disciplina, a prática dos valores, o cuidado com a integridade física, é assim que eu poderia estar resumindo, digamos assim, o cerne da minha prática profissional." (Entrevista realizada em 25/11/2016).

Revela-se a ampliação da consciência sobre a atividade em relação a aspectos considerados centrais (motivação, disciplina, prática de valores) apesar de não haver uma reflexão da docente sobre os aspectos mencionados. Trata-se deelementos da prática educativa (gênero profissional) ligados à gestão da turma que contrastam com a pouca ênfase dada, ao longo das entrevistas, ao processo de alfabetização, apesar deste ser uma prescrição central para o primeiro ano do ensino fundamental, e à mobilização intelectual dos alunos, essencial no processo de ensino-aprendizagem.

A pesquisadora sentiu necessidade de fazer questionamentos com o intuito de provocar mobilização da docente sobre sua prática, tendo em vista a fixação desta última nos impedimentos da atividade, conforme diálogo a seguir:

Pesquisadora: Levando em consideração essa atividade da carta pro Papai Noel, que possibilidades você acha que poderiam ser postas em prática pra contribuir nessa...

\section{S: Produção?}

Pesquisadora: Motivação dos alunos no prazer de aprender.

$$
\text { S: } A h \text {. }
$$

A pergunta foi feita em função da ênfase dada por $\mathbf{S}$ à motivação pelo prazer de aprender e às constantes referências ao desinteresse dos alunos, revelando os entraves da atividade. A proposta inicial de carta envolvia a cópia de um modelo no quadro com lacunas a serem preenchidas. $\mathrm{O}$ diálogo ressalta o foco no prescrito enquanto produção, no entanto o questionamento engendrou novas ideias por parte da docente, tais como trabalhar palavras escolhidas pelas crianças relativas a brinquedos que gostariam de ganhar, inclusão dos nomes dos familiares, do lugar onde se mora e número de pessoas com quem se vive. Essas estratégias (gênero profissional) exploram a aprendizagem e dão sentido à carta da criança (dimensão interpessoal), trazendo-a para a sua realidade e envolvendo sua participação e elaboração.

A segunda profissional entrevistada, que será chamada de $\mathrm{M}$, pertence ao perfil de baixo risco psicossocial e reconhece um alto suporte social no trabalho. A docente tem 51 anos, leciona há 21 , possui uma turma com 22 alunos, trabalha os dois turnos na mesma instituição e mora perto do local de trabalho. Durante a etapa de escolha da 
situação a ser explorada pela instrução ao sósia, M trouxe a alfabetização e o letramento como focos de sua atuação (prescrito e gênero profissional). A situação escolhida por M para ser explorada foi o momento após o intervalo, considerado desafiante pela agitação dos alunos e necessidade de retomarem a concentração.

Durante a instrução, $\mathrm{M}$ apresentou instrumentos de regulação para auxiliar os alunos a relaxarem, como a respiração e a contagem (gênero profissional), que orientam a atenção e a consciência da criança, dando suporte à prática. Em seu relato, $M$ trouxe que costuma instruir as crianças (dimensão pessoal e interpessoal) reforçando a necessidade da concentração para aprender melhor, enfocando a aprendizagem dos alunos como norte (prescrito). No decorrer da instrução, a professora trouxe que dois alunos demoram a voltar à sala após o intervalo, constituindo um desafio que a docente contorna pedindo ao ajudante do dia (prática constitutiva do gênero profissional) que chame os atrasados. Em relação a brigas ou agressões de alunos trazidas após o intervalo, M menciona o combinado feito entre as professoras (coletivo) de conversar com as crianças para que elas peçam desculpas e pensem no que vão fazer para melhorar, podendo perder o direito ao intervalo caso a situação se repita. $\mathrm{O}$ gênero profissional é mobilizado e estilizações são criadas como formas de responder aos desafios da realidade, sustentando a ação, evitando o isolamento e que se fique "sem voz" face ao real.

$\mathrm{M}$ também trouxe que, por uma falha do sistema, a escola não recebeu livros didáticos suficientes para o primeiro ano do ensino fundamental e sua turma ficou sem acesso aos mesmos, o que a levou a ter de pesquisar suas atividades em outras fontes, constituindo um desafio à ação. A docente mencionou "os direitos de aprendizagem" referidos nos cursos do PNAIC comoorientação para a ação (prescrito, gênero profissional), relatando o seguinte sobre a escolha dos materiais:

De preferência aquele que tenha uma interatividade maior, em que ele possa usar o que ele sabe pra aprender o que ele não sabe. É um princípio do... Do PNAIC, né? Considerar o conhecimento que ele tem, mas adquirir o conhecimento científico, né?(Entrevista realizada em 07/11/2016).

A busca por atividades interativas (dimensão interpessoal) revela foco no papel ativo do aluno. O PNAIC parece atuar como recurso para o enriquecimento do gênero profissional através de saberes teóricos, como partir do que o aluno sabe para alcançar o que ele não sabe, referente ao conceito de zona de desenvolvimento proximal, de Vigotski, além da busca pela apropriação do conhecimento científico, ampliando a compreensão do processo de ensino-aprendizagem e das possibilidades de atuação.

$\mathrm{M}$ refere-se ainda ao fato de que os livros disponibilizados na escola para o primeiro ano não seguem as orientações do PNAIC e que não ter livro acabou revelando-se positivo, embora não sem custos: "Dificultou porque eu tenho que pesquisar muito... Dificultou nesse aspecto, mas por outro... facilitou até a questão da alfabetização, porque você não fica preso a um livro. Às vezes atrapalha muito o professor essa questão".

Uma dificuldade converteu-se, embora não sem custos, em ampliação da autonomia de $\mathrm{M}$, permitindo o desenvolvimento de sua atividade, ampliando a potência de ação em relação à alfabetização. Evidencia-se o lugar de prescrição atribuído ao livro didático e suas possibilidades de aprisionamento da atividade, embora possa ser também instrumento de suporte e enriquecimentoda prática profissional.

Na segunda entrevista, momento de confrontação a trechos da instrução, $\mathrm{M}$ trouxe que a leitura da transcrição da instrução ao sósia motivou algumas adaptações de sua prática em relação aos alunos que não voltavam logo após o intervalo. A docente colocou que os desafios para trazê-los à sala eram maiores do que os expostos, exigindo mobilizações que afetavam seu tempo e atividade (dimensão pessoal). Houve, então, mais firmeza e advertência da possibilidade de perda do direito ao intervalo (dimensão interpessoal), o que gerou menos atrasos.

M trouxe que as professoras do primeiro ano que estão fazendo curso do PNAIC reclamam do livro didático, considerado pela docente como tradicional, pois ele não é coerente com os princípios do programa. Evidenciam-se conflitos entre prescrições para o trabalho que constituem facetas diferentes e possivelmente contraditórias que constituem ogênero profissional. A docente trouxe ainda a importância da experiência para julgar quando um livro ajuda e quando ele atrapalha, enfatizando a contribuição dos cursos feitos pelo PNAIC no enriquecimento dessa experiência e capacidade avaliativa, evidenciando aconstrução de referenciais para a ação.

Sobre a experiência com as entrevistas realizadas, M coloca:

A oportunidade de refletir sobre a prática é muito bom, né? A gente já faz muito isso nos encontros do PNAIC... de ver a prática de outros professores e discutir, né. Faz assim, não faz assim, porque assim não deu certo, porque assim deu certo.

Essa questão de você conciliar o letramento e a alfabetização, eu vim aprender nos últimos anos, na prática, fazendo curso, cursos do PNAIC, observando a prática de outros professores, né. (Entrevista realizada em 30/11/2016)

Os cursos do PNAIC, na fala de M, trazem a reflexão e discussão ligadas a um coletivo de trabalho, o compartilhamento de práticas e experiências tendo em vista o trabalho bem feito: "assim deu certo", "assim não deu certo", além da questão da conciliação do letramento e alfabetização, favorecendo o enriquecimento dogênero profissionale permitindo o desenvolvimento de referenciais para a ação. M ainda coloca:

Então assim, Meu Deus do Céu! Eu acho que eu tenho experiência pra dar um curso. Eu nunca parei pra pensar 
como é interessante a gente conversar com alguém sobre a experiência da gente. Apesar de a gente discutir no PNAIC... me fez perceber isso aí. Que eu tenho muita experiência, uma experiência que é baseada na teoria, mas também aprendi muito com a prática. Né, então a ponte entre teoria e prática foi importante pra mim.

O trecho revela a ampliação da consciência sobre a atividade pela reflexão e diálogo com esta, trazendo a experiência profissional fundamentada na relação teoria-prática, condição de produção de consciência sobre a atividade na contramão da alienação.

Em sua colocação final, $M$ menciona a situação difícil da educação pública no país, trazendo o número limite de alunos ainda elevado para alfabetizar em uma turma só (25), além dos baixos salários. No entanto a docente diz:

Eu tenho muito prazer em trabalhar no que eu faço,...em alfabetizar, né? E eu digo muito isso aos meus alunos, que eu aprendo todo dia com eles, né? E também tenho as minhas dificuldades que são inúmeras, inúmeras, mas eu acho que os ganhos que eu tenho em sala de aula... Ganho que eu falo, ganho de ver uma criança aprendendo a ler, né?...Hoje eu saber que tem $80 \%$ já lendo... Eu fico feliz demais, né, pra mim isso aí era pra ser... É um motivo de orgulho pra mim.

Ao colocar que aprende com os alunos, M enfoca a dimensão interpessoal da atividade e a produção de desenvolvimento na relação com o outro e com os desafios do real, que ao invés de gerar entraves, geram potência de ação, pois encontram suporte na dimensão histórica e coletiva do gênero profissional. A satisfação e orgulho no trabalho são trazidos tendo em vista a percepção de realização de um trabalho bem feito.

A análise dos trechos de acordo com as instâncias de referência da atividade (pessoal, interpessoal, impessoal/ prescrito, transpessoal/gênero profissional) revelou elementos de sua dinâmica e vivência pelas professoras. Estes aspectos estão relacionados a condições objetivas contextuais que compõem as vivências da atividade, tais a experiência prévia de docência em sala superlotada com crianças em condições heterogêneas de aprendizagem e falta de suporte, a ausência de livros didáticos ou disponibilização de livros incoerentes com as orientações seguidas, questões relativas à dupla jornada, deslocamento e tempo, e à própria complexidade do processo ensino-aprendizagem e de alfabetização.

As condições de trabalho e história de S favoreceram a produção de uma vivênciada sala de aula como campo de batalha, lugar de trabalho e produção à revelia dos desafios e dos próprios alunos, situação enrijecedora tendo em vista que os alunos devem ser co-construtores do processo de ensino-aprendizagem. O prescrito para a atividade de $S$ foi a produção, dimensão que aprisionou as outras em uma lógica de controle rígida, sem espaço para a criatividade e o desenvolvimento. Observou-se ainda a escassez de mediações do gênero profissional na atividade da docente, encontrada solitária, "sem voz" face ao real. Ilustra-se uma atividade impedida geradora de sofrimento.

Por sua vez, M traz a construção e desenvolvimento de saberes de referência para a atuação (gênero profissional) construídos na prática, formações e discussões com coletivos de trabalho, permitindo-lhe lidar com os desafios com autonomia e criatividade, gerando a percepção de um trabalho bem feito. $\mathrm{O}$ prescrito para a atividade de $\mathrm{M}$ foram a alfabetização e letramento dos alunos, o processo de ensino-aprendizagem, instância relacionada de modo dinâmico e criativo com as outras produzindo potência de ação. $O$ coletivo, através do gênero profissional, permeia o trabalho de $\mathrm{M}$, configurando uma atividade potencialmente produtora de saúde e desenvolvimento.

Em relação ao PNAIC, apesar da formação poder constituir recursos para o desenvolvimento da atividade (trocas e discussões em grupo, ligação teoria-prática), isto não ocorre necessariamentetendo em vista a coexistência de condições difíceis de trabalho capazes de atravancar o desenvolvimento e produzir sofrimento e alienação. $M$ também menciona que as formações do PNAIC ocorrem geralmente nos fins de semana, momento de descanso e planejamento para muitos professores, podendo desmobilizá-los no comparecimento aos encontros ou na opção por seguir a formação. Evidenciam-se ainda contradições nas orientações/prescrições do sistema educativo, compondo um cenário fragmentado. A rede que oferece cursos do PNAIC é a mesma que disponibiliza livros didáticos alheios aos seus princípios.

\section{Considerações Finais}

A clínica da atividade revela-se uma abordagem capaz de dar vislumbres da vivência da atividade laboral (prisma) e, embora o contexto de aplicação não tenha sido ideal para a promoção de vivência dramática/transformadora, há potencial para isto, sobretudo se a intervenção for coletiva,considerando que houve ampliação, embora discreta, da consciência das docentes sobre suas atividades.

As entrevistas não esgotam a vivência da atividade dos sujeitos, mas apontam para sua construção e relacionamento com a atividade (prisma). As vivências são mediadas por elementos do contexto social e político mais amplo que se relacionam com os lugares ocupados pelas docentes, expressando diferentes possibilidades diante da realidade contraditória da educação pública. O adoecimento docente, por exemplo, está relacionado aos interesses contraditórios em jogo que prescrevem o fracasso escolar, no entanto há também forças apoiadas em elementos contextuais que, apesar das dificuldades, produzem desenvolvimento da atividade no sentido de uma educação potencialmente emancipadora. Nesse sentido, destaca-se a necessidade e importância da criação de coletivos de trabalho nas instituições de ensino, espaços de troca, discussão e conexão teoria-prática, capazes de produzir referenciais para a ação no enfrentamento 
da realidade, sem deixar de lado e implicando a mobilização na luta por melhores condições de trabalho.

\section{Referências}

Alferes, M. A.; Mainardes, J. (2014). Análise preliminar do documento "Elementos conceituais e metodológicos para definição dos direitos de aprendizagem e desenvolvimento do ciclo de alfabetização $\left(1^{\circ}\right.$, $2^{\circ}$ e $3^{\circ}$ anos) do Ensino Fundamental". Currículo sem Fronteiras, 14(1), 243-259.

Asbahr, F. S. F. (2005). Sentido pessoal e projeto político pedagógico: Análise da atividade pedagógica a partir da psicologia históricocultural. Dissertação de mestrado, Universidade de São Paulo, São Paulo.

Canguilhem, G. (2009). O normal e o patológico (M. T. R. C. Barrocas, Trad.). Rio de Janeiro: Forense Universitária. (Trabalho original publicado em 1966).

Charlot, B. (2008). O professor na sociedade contemporânea. Revista da FAEEBA - Educação e Contemporaneidade, 17(30), 17-31.

Clot, Y. (1999). La fonction psychologique du travail. Paris: Presses Universitaires de France.

Clot, Y. (2002). Clínica da atividade e repetição. Cliniques Méditerranéennes, 66 .

Clot, Y. (2008). Travail et pouvoir d'agir. Paris: Presses Universitaires de France.

DARES-DRESS (2008). Les Facteurs Psychosociaux au Travail: Une évaluation par le questionnaire de Karasek dans l'enquête Sumer 2003. Première Synthèses, 22, 1-8.

Dourado, L. F.; Oliveira, J. F. (2009). A qualidade da educação: perspectivas e desafios. Cadernos Cedes, 29 (78), 201-215.
Leontiev, A. (2004). O desenvolvimento do psiquismo ( $\mathrm{H}$. Roballo, Trad.). São Paulo: Centauro. (Trabalho original publicado em 1974).

Lopes, E. C. P. M.; Caprio, M. (2008). As influências do modelo neoliberal na educação. Revista online de Política e Gestão Educacional, 5.

Mainardes, J.; Stremel, S. (2012). A organização da escolaridade em ciclos no contexto do ensino fundamental de nove anos: reflexões e perspectivas. Jornal de políticas educacionais, (11), 3-11.

Moretti, V. D.; Asbahr, F. S. F.; Rigon, A. (2011). O humano no homem: os pressupostos teórico-metodológicos da teoria histórico-cultural. Psicologia \& Sociedade, 23(3), 477-485.

Paparelli, R. (2009). Desgaste mental do professor da rede pública de ensino: trabalho sem sentido sob a política de regularização de fluxo escolar. Tese de doutorado, Universidade de São Paulo, São Paulo.

Paro, V. H. (1993). A natureza do trabalho pedagógico. Revista da Faculdade de Educação, 19(1), 103-109.

Saviani, D. (2000). Pedagogia histórico-crítica (7 $7^{\mathrm{a}}$ ed.). Campinas: Autores Associados.

Silva, C. O. D.; Ramminger, T. (2014). O trabalho como operador de saúde. Ciências \& Saúde Coletiva, 19(12), 4751-4758. Recuperado: 15 jan. 2016. Disponível: http://www.scielo.br/scielo. php?script=sci_arttext\&pid=S1413-81232014001204751

Veresov, N. (2014). Émotions, perezhivanie et développement culturel: le projet inachevé de Lev Vygostki. In: Moro,C.; Mirza, N. M. (Orgs.),Sémiotique, culture et développement psychologique (pp. 209-235). Villeneuve d'Ascq: Presses Universitaires du Septentrion. unrestricted use, distribution and reproduction in any medium, provided the original article is properly cited. 